\title{
Quantitative Evaluation Research of Value for Money of PPP Projects for Logistics Parks in Ethnic Areas
}

\author{
Yifan Zhang ${ }^{a}$, Lei Jiang ${ }^{b}$ *, Luzi Zhang ${ }^{c}$, Huining Hu ${ }^{d}$, Jie Zhang ${ }^{\mathrm{e}}$ \\ and Haoran Zhou ${ }^{\text {f }}$ \\ School of Civil Engineering, Dalian Minzu University, Dalian 116600, China. \\ a1504612716@qq.com, b52263977@qq.com, ' $1030323760 @ q q . c o m,{ }^{d} 1055152436 @ q q . c o m,{ }^{e} 1$ \\ 030813219@qq.com, 11841747725@qq.com
}

\begin{abstract}
The PPP model, a new financing model emerged after the 1990s, refers to jointly provide public products or services to the public sector through the establishment of partnerships between the public sector and the private sector. However, the PPP model is only one of the choices for supply of infrastructure products or services. The government cannot subjectively affirm a certain purchasing model nor can it deny a certain model. There should be a scientific quantifiable basis to judge whether the model is worthwhile or not. After the calculation of the PSC and PPP values for infrastructure PPP project of the logistics park in ethnic areas, this research got the VFM value, which provides a foundation for the financial management of the PPP project as well as provides a reference for the implementation of the project.
\end{abstract}

key words: PPP project, VFM, PSC

\section{Introduction}

Value for money evaluation is a kind of method that could assess whether to adopt the PPP model instead of the government's traditional purchasing model to the implementation for public service projects [1-2]. The government's traditional purchasing model means that the government and its affiliates are directly responsible for the design, investment and financing, construction, operation and maintenance (including consign other people to carry out some part of these tasks) of the project, and assume the project's main risks. The traditional government purchasing model is a project development model that generally does not implement the concept of whole life cycle management.

The core of value for money evaluation is to determine the necessity of using PPP model to supply public services [3]. It is possible to avoid the blind adoption of PPP model in projects and 
to optimize the allocation as well as the utilization efficiency of public resources by using value for money evaluation.

The value for money evaluation should abides by a principle of truth, fairness, objectivity, and impartiality to determine whether the PPP model adopting by the project is more valuable than the government's traditional procurement model.

Value for money evaluation considers the costs and risks of different plans through the life cycle of a project. These costs and risks include qualitative evaluations and quantitative evaluations (Public Sector Comparator). The results of value for money evaluation are generally used as a foundation for whether to adopt PPP and determine risk sharing [4].

\section{Projects Background}

The project, located in a certain area of Inner Mongolia Autonomous Region, and its construction includes road engineering, water supply engineering, drainage engineering, reclaimed water engineering, electric power, communication engineering, heating supply engineering, natural gas engineering, road greening, road lighting and Traffic engineering attached to road project and so on.

This project uses the BOT operation mode in the PPP model [5]. The specific implementation method of the mode is that the People's Government authorizes the Municipal Bureau of Commerce and social capital to jointly set up a project company, which will be used as the main body of the legal entity to implement the infrastructure construction project of the logistics park in the ethnic region. The people's government grants the project company with a operating right for 15 years. During the period of cooperation, the project company is responsible for the design, investment and financing and construction of infrastructure engineering projects for the logistics parks in ethnic areas, as well as the run and management of the company. At the same time, during the project cooperation period, social capital, through the PPP model, participates in the financing, operation, maintenance, and update management of the entire life cycle for the project to achieve life cycle integration After the end of the cooperative operation period, the project assets and facilities will be transferred to the government or its designated organizations.

\section{Value for Money Evaluation}

Under the assume that the PPP model and the government's traditional procurement model have the same output performance, the judgement of whether the PPP model can reduce the project life cycle cost has been determined according to the "PPP Value for Money Evaluation Guidelines (Trial)" (Cai Jin [2015] No. 167) requirements, through the comparison between the net present value of government expenditure costs (PPP value) for the entire life cycle of the PPP project and the value of public sector comparison (PSC value).

\subsection{PSC Measurement}

The PSC value refers to the net present value of the life cycle cost for the traditional model used by the government, providing the same infrastructure and public service requirements as the requirement of PPP project output specification.

PSC value $=$ initial PSC value + competitive neutral adjustment value + bearing cost of transferable risk + bearing cost of self-retention risk 


\section{(1) Initial PSC value}

The initial PSC value means the sum of the net present value of the costs including the construction cost and the cost of operation and maintenance of the reference project implemented by the government.

a.The net value of the construction

When the government (or the company or organization authorized by it) invests in and constructs the project, it needs to provide all the investment for the project. The construction cost , totaling 381.06 million yuan, includes the cost of project, other expenses for construction of the project, budget reserve, and interests during construction period. These funds are invested in three years. In the first year, they invested 102.56 million yuan, in the second year they invested 173.50 million yuan, and in the third year they invested 105 million yuan.

b. the net value of the operation and maintenance

The project operation and maintenance costs are measured under the assumement that the government's traditional purchasing model is the same as the PPP model. The costs of operation and maintenance for the project are mainly composed of fuel consumption, staff salaries and welfare expenses, and maintenance costs. The annual maintenance cost of the project operation totals 2.72 million yuan/year, and the operation period is 12 years. Therefore, the total net cost of project maintenance is 3264 million yuan.

(2) Competitive neutral adjustment value

A total expense of 21.75 million yuan considered by using of the PPP mode including operating tax and surcharge, tax on added value, and income tax during the operation during the period of the project company, of which business tax and surcharge is 0 yuan, tax on added value is 0.000 yuan, and income tax is 21.75 million yuan.

(3) Cost of transferable risk and self-retention risk

The cost of transferable risk and self-retention risk. The transferable risk means the total value of all risks transferred to the social capital, while the residual risk refers to all the risk values that cannot be transferred to the social capital.

cost of risk assumption $=$ cost for project construction and operating $\times$ proportion of risk assumption cost

In general PPP project practice ,it is usually that the cost of risk assumption does not exceed $20 \%$ of the cost of project construction and operation, cost of transferable risk accounts for $90 \%$ of the project's total risk-taking costs, and the cost of self-retention risk accounts for $10 \%$ of the project's total risk-taking costs. .

Considering a discount rate of $5.00 \%$, the Public sector comparative value is 45.01 million yuan when government uses traditional purchasing model.

\subsection{PPP Value}

The PPP value refers to the net present value of the life cycle cost assumed by the government when it implements the PPP project. Under the PPP model, the project company jointly established by the government and social capital is responsible for investment construction, operation and maintenance. The specific financial calculations are as follows:

(1) Government fiscal expenditure

a. Equity investment expenditure 
The government's equity expenditure is 25.35 million yuan with a time of mean expenditure for 3 years.

b. Government subsidy expenditure

During the operation period, the government bears total subsidies for 57.76 million yuan.

(2) The government's self-retention risk assumption cost is equal to the expenditure responsibility of life cycle risk-bearing in the PPP value. During the entire cooperation period, the bearing cost for government's self-retention risk is 8.22 million yuan.

Considering a discount rate of $5.00 \%$, the government's total net life cycle cost (PPP) is 37.4 million yuan.

\subsection{Value for Money}

According to the above comparison between the government's traditional purchasing model (PSC) and the net present value of government life cycle cost under the PPP model, the net present value of government life cycle cost under the PPP model is less than the public sector comparative value. The value of VFM for this project can be calculated as follows:

VFM = PSC-PPP = 45011-37420 = 75.91 million yuan $>0$

The value of value for money in this project exceeds zero, that' $\mathrm{s}$ to say, PPP mode is suitable for operation of the project.

\section{Conclusions}

This paper quantitatively analyzed the value for money of the project by using uses the PPP project in ethnic areas as an example. the VFM value of the project is obtained after the calculation for the PSC value and PPP value of the project. Because of VFM is greater exceeds zero, PPP mode is suitable for operation of the project from the perspective of quantitative analysis about value for money. This paper calculated the value for money of PPP by using a specific project, and provides experience and reference for the personnel and researchers working on PPP projects.

\section{Acknowledgments}

This work was financially supported by Innovation and Entrepreneurship Training Program of Dalian Minzu University (National Level 201812026036).

\section{References}

[1] Guidebook for Value for Money Assessment[R]. Federal Highway Administration, U.S. Department of Transportation, 2013-12.

[2] National Public Private Partnership Guidelines: Overview[R]. Infrastructure Australia, 200812. NCPP.

[3] National Public Private Partnership Guidelines: Volume 1: Procurement Options Analysis[R]. Infrastructure Australia, 2008-12.

[4] Quantitative assessment: user guide[R]. HM Treasury, 2011-12.

[5] Quantitative assessment: user guide spreadsheet[R]. HM Treasury, 2011-12. 